$X$ - $r$ ay St udi es on Long Chai $n$ Compounds sol i dified under an Alternating El ectric Fi eld

\begin{tabular}{|c|c|}
\hline 著者 & I da Mtsuo \\
\hline 著者別表示 & 井田 光雄 \\
\hline $\begin{array}{l}\text { jour nal or } \\
\text { publ i cat } i \text { on } \mathrm{title}\end{array}$ & $\begin{array}{l}\text { The sci ence reports of the Kanazawa Uni versity } \\
=\text { 金沢大学理科報告 }\end{array}$ \\
\hline vol une & 3 \\
\hline number & 2 \\
\hline page $r$ ange & $231-235$ \\
\hline year & 1955-07- 01 \\
\hline URL & ht t p: //doi . or g/10. 24517/00011510 \\
\hline
\end{tabular}


The Science Reports of the Kanazawa University, Vol. III, No. 2, pp. 231-235 July, 1955

\title{
X-ray Studies on Long Chain Compounds Solidified under an Alternating Electric Field
}

\author{
By \\ Mitsuo IDA \\ (Received January 25, 1955)
}

\section{Introduction}

$\mathrm{X}$-ray studies on the fibre structure of long chain compounds solidified under an electrostatic field were performed systematically by Kakiuchi, (1) but similar studies using an alternating electric field seem never to have been made by any author so far as the present author knows. The effect of an alternating electric field on liquid crystalline $p$ - azoxyanisol was reported by Kast. (2)

The author supposed that even if a long chain compound is solidified under an alternating electric field it would assume fibre structure owing to the anisotropy of the induced polarization provided the microcrystal had no permanent resultant dipole moment, and verified the correctness of the supposition by means of $\mathrm{X}$-ray diffraction.

\section{Experimental Procedure and Results}

The sample solidified between two nickel electrodes (diammeter : $12 \mathrm{~mm}$ ) was torn off and cut perpendicularly to the plane into a thin plate (thickness : $0.5 \mathrm{~mm}$ ). The $\mathrm{X}$-ray from a copper target was radiated without filter in a direction perpendicular to the electric field applied to the sample. The sample-plate distance was $4.6 \mathrm{~cm}$.

An alternating electric field of $60 \mathrm{c} / \mathrm{s}$ frequency and another of about $300 \mathrm{k} . \mathrm{c} / \mathrm{s}$ frequency generated by means of the apparatus shown in Fig. 1 were used as well as

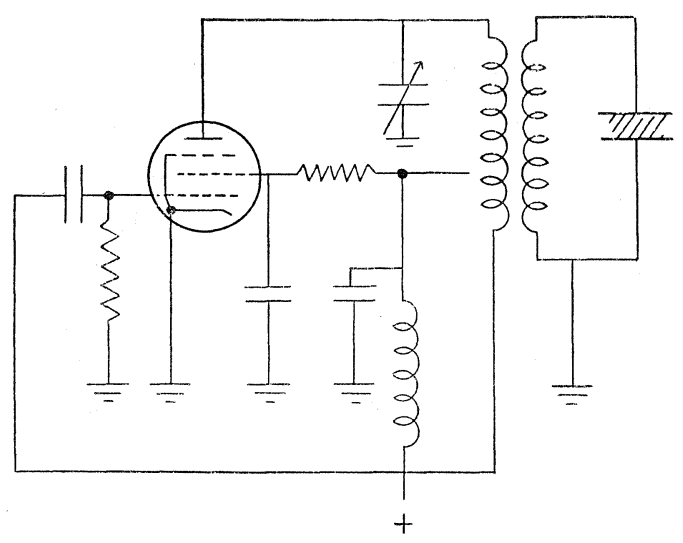

a constant electrostatic field for comparison. The intensity of the field was $6-8 \mathrm{kv} / \mathrm{cm}$. Crude commercial sample was used in every case.

It was found that the Debye rings obtained could be classified into three types, namely, type A which has intensity maxima in the direction of the electric field (Fig. 3, Fig. 5), and type $\mathrm{B}$ which has intensity maxima in the direction perpendicular to it

Fig. 1. High frequency oscillator 
(Fig. 2, Fig. 4), and type $\mathrm{C}$ with uniform rings. The results are tabulated below. Table

\begin{tabular}{|c|c|c|c|}
\hline 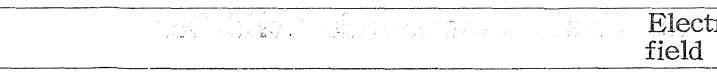 & trostatic & $60 \mathrm{c} / \mathrm{s}$ & $300 \mathrm{kc} / \mathrm{s}$ \\
\hline Paraffin & A & B ? & $\mathrm{B}$ ? \\
\hline Cetyl alcohol & $\mathrm{A}$ & No & No \\
\hline Stearic acid & A & $\mathrm{A}$ & A \\
\hline Palmitic acid (containing a few percent of paraffin) & $\mathrm{A}$ & $\mathrm{B}$ & $\mathrm{B}$ \\
\hline Ethylstearate & A & A & $\mathrm{A}$ \\
\hline Cetylpalmitate (containing a few percent of paraffin) & A & A & A \\
\hline Yellow wax & A & $\mathrm{B}$ & $\mathrm{A}$ \\
\hline White wax & A & B & B \\
\hline Carnauba wax & A & $\mathrm{B}$ ? & B? \\
\hline Japan wax & $\mathrm{A}$ & No & No \\
\hline
\end{tabular}

\section{Discussions}

The present author's classification was made by the intensity maximum of Debye ring. corresponding to the (110) plane which gave the'strongest reflection. Therefore both the A type ( $a$ axis perpendicular to the direction of the electric field) and the B type ( $a$ axis parallel to the electric field) in the Kakiuchi's classification belong to our A type.

The author's tentative explanation of the preceding experimental results is as follows.

Microcrystals of cetyl alcohol probably have permanent dipole moment as Kakiuchi believes, (1) and its direction must be perpendicular to the long chain. And so the chains will orient perpendicular to the electrostatic field. But in an alternating electric field the chains will not orient on account of the permanent dipole moment.' This is the reason why cetyl alcohol shows $A$ type in an electrostatic field and a uniform ring in an alternating electric field.
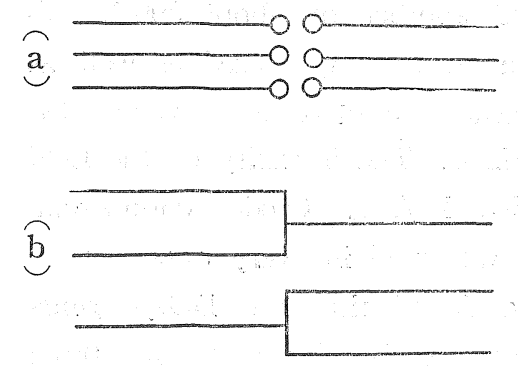

Fig.6. Double chain-length structure
But in the other substances the microcrystals seem to lack permanent dipole moment for the following reasons.

(a) The paraffin molecule is non-polar.

(b) Aliphatic acids and esters are well known to form a double chain-length structures shown in Fig. 6 a so that dipole moment are cancelled.

(c) The main constituent of yellow wax and white wax are melissylpalmitates and that of carnauba

wax is melissylcerotate

(d) Palmitic acid and cetylpalmitate were mixed with a few percent of paraffin in order to reduce the size of the microcrystals so as to make their fibre structure clearer. Such mixing is only mechanical and will not change the crystal structure. (3)

(e) The main constituent of Japan wax is tripalmitine for which Lutton and others (4), (5) 
suggested the double chain-length structure as shown in Fig. $6 \mathrm{~b}$ and so the microcrystals of this substance will have no resultant electric moment.

The reasons why the microcrystals of these substances orient in an electric field in spite of zero dipole moment may be due to their anisotropic induced polarization. But clear conclusion has not yet been obtained for the reason why there only A type occurs in the case of an electrostatic field, while the three types A, B, and uniform ring occur in an alternating electric field. Only the following supposition seems to be justified.

According to Silberstein's theory (6) it is natural to think that the polarizability of a long chain molecule is larger in the direction of chain axis than perpendicular to it, Nevertheless the chains always orient perpendicular to the direction of an electrostatic field. This seems to be due to the following mechanism.

In the process of solidification the ions contained in the liquid sample will assemble near the microcrystals as shown in Fig. 7, and the microcrystals will be polarized anew by the local field due to the ions besides the external field. Now we assume that the

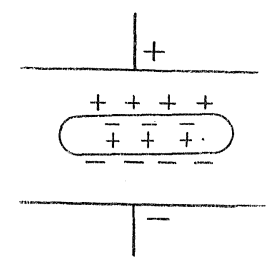

Fig. 7. microcrystals are elongated along the chain axis, and so the intensity of the local field is stronger when the long chains orient in the direction perpendicular to the external field than otherwise. Therefore the long chain will orient in the direction perpendicular to the external field influenced more by the local field rather than its anisotropic polarizability . This is the case of A type in an electrostatic field. In the case of an alternating electric field if the ions near the microcrystals can be quickly replaced by ions of the opposite sign in step with the frequency of the alternating electric field, the chains will still orient in the direction perpendicular to the external field. But when the ions can not be exchanged quickly on account mainly of insufficiency of the number of ions, the effects of positive and negative ions are cancelled and the molecules will be polarized mainly by the external field, and the chain will orient in the direction of the external field. This is the case of $B$ type.

If both the above mentioned causes of $\mathrm{A}$ type and $\mathrm{B}$ type are present and cancelled each other or the anisotropic polarizability of molecule is not so conspicious, nearly uniform rings will appear. For example they are seen in carnauba wax and Japan wax.

In addition some few details will be given. White wax showed $\mathrm{A}$ type by the alternating electric field of low frequency $1.5 \mathrm{c} / \mathrm{s}$, and when a minute quantity of $\mathrm{CuSO}_{4}$ • $5 \mathrm{H}_{2} \mathrm{O}$ is added to it showed $\mathrm{A}$ type also by the high frequency electric field.

Paraffin somtimes showed A type by the alternating electric field. Generally it seemed that the case of $B$ type is comparatively rare in the limited number of substances we used.

As shown in Fig. 2 B type of paraffin is not conspicious, so the author tried to calculate the anisotropy of the polarizability of paraffin from the bond polarizabilities. The calculation depended upon the Stein's work on the n-pentane.(7) But it was only on a n-paraffin containing $n$ carbon atoms of completely streched out planar zig-zag 
conffigulation which is formed in the solid state. Let $\mathrm{P}_{1}$ be the polarizability in the direction of chain axis, $\mathrm{P}_{2}$ that in the direction perpendicular to it in the plane of the chain and $\mathrm{P}_{3}$ that in the direction perpendicular to both, then we can obtain the following values.

$$
\begin{aligned}
& \mathrm{P}_{1}=(24.2 \mathrm{n}+1.8) \times 10^{24} \mathrm{~cm}^{3} \\
& \mathrm{P}_{2}=(19.4 \mathrm{n}+6.6) \times 10^{24} \mathrm{~cm}^{3} \\
& \mathrm{P}_{3}=(14.6 \mathrm{n}+11.4) \times 10^{24} \mathrm{~cm}^{3} \\
& \text { If we put } \mathrm{n}=20, \text { then } \mathrm{P}_{1}: \mathrm{P}_{2}: \mathrm{P}_{3}=49: 39: 30
\end{aligned}
$$

Thus we can know that the anisotropy of the polarizability of n-paraffin is not so conspicious and even in the best condition the fibre structure of $\mathrm{B}$ type will not be so marked.

The author wishes to express his sincere thanks to Professor H. Shoji for his kind guidance. He also expresses his gratitude to Mr. T. Tomoyasu for his cooperation.

A part of the expences of the experiment was defrayed by Nishikawa Co. to which thanks are due.

\section{References}

(1) Kakiuchi : Sci. Pap. I. P. C. R. 40 (1943) 189.

(2) Kast : Z. f. Phys. 71 (1931) 39.

(3) Yosida : Proc. Imp. Acad. Tokyo 18 (1942) 377.

(4) Lutton : J. Am. Chem. Soc. 67 (1945) 524.

(5) Clarkson \& Malkin : J. Chem. Soc. (1934) 666.

(6) Silberstein : Phil. Mag. 33 (1927) 92, 215, 521.

(7) Stein : J. Chem. Phys. 21 (1953) 1193. 


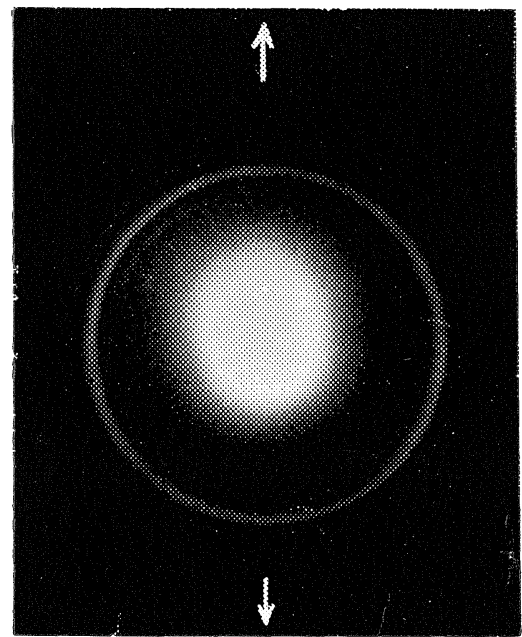

Fig. 2. Paraffin $(300 \mathrm{kc} / \mathrm{s})$

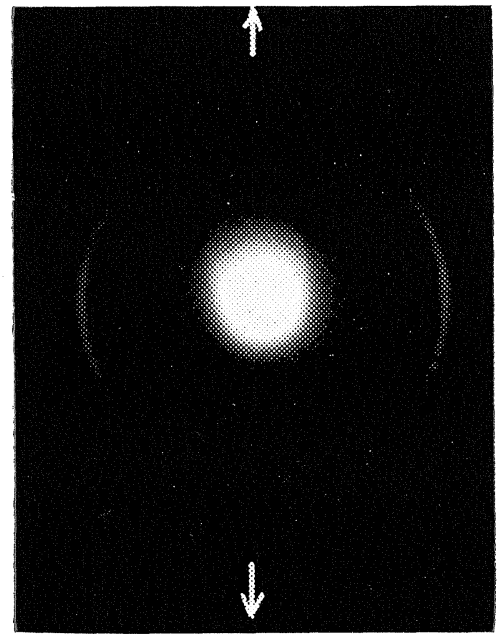

Fig. 4. White wax $(60 \mathrm{c} / \mathrm{s})$

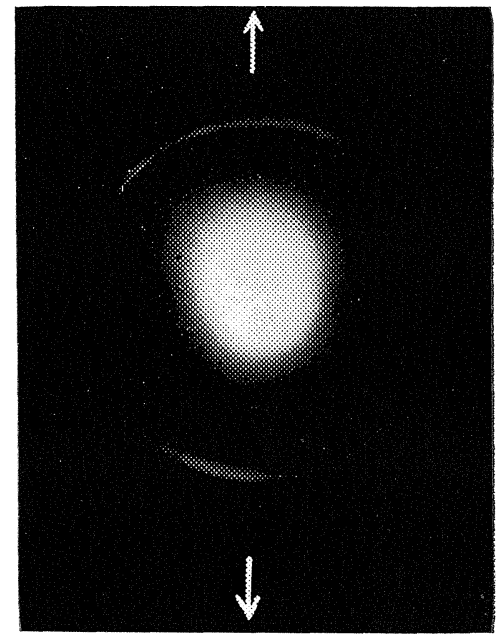

Fig. 3. Ethylstearate $(60 \mathrm{c} / \mathrm{s})$

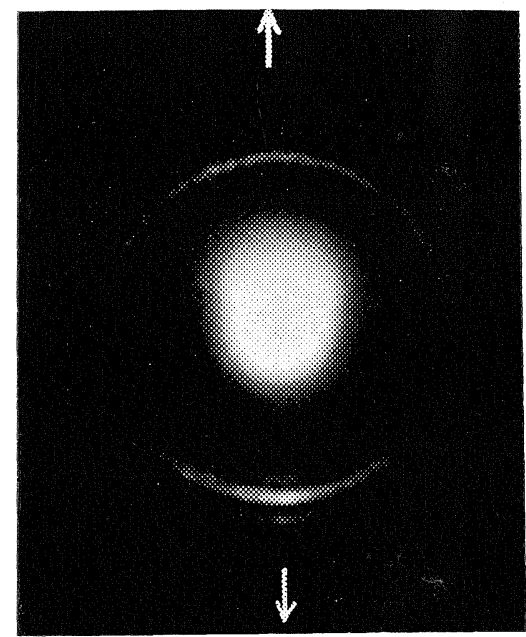

Fig. 5. Cetylpalmitate $(300 \mathrm{kc} / \mathrm{s})$ 